\title{
The impact of self-targeted subsidies on social welfare in Iran
}

\author{
Parinaz Koozehgar $^{\mathrm{a}^{*}}$, Ghorban Mohammad Pourghaz ${ }^{\mathrm{b}}$ and Seyyed Rafie Mousavi Ortaboulagi ${ }^{\mathrm{c}}$
}

${ }^{a}$ Department of Management and Social Sciences, North branch, Islamic Azad University, Tehran, Iran

${ }^{b}$ Economics in the field of Management / Economics of Enterprises, Tehran, Iran

${ }^{c}$ M.Sc. In Management

\section{H R O N I C L E}

Article history:

Received January 4, 2014

Accepted 1 June 2014

Available online

June 32014

Keywords:

Self-targeted Subsidies

Social Welfare

Income Deciles

Atkinson Social Welfare Function

Social Inequality Aversion

Parameter

\begin{abstract}
A B S T R A C T
Society welfare plays essential role on supporting poor and low income deciles governments normally pay subsidies on different goods to decrease the prices and as a result, increase purchasing power. However, due to lack of a good target, the relatively rich and high income deciles benefit more than the poor from subsidies do. Therefore, it seems necessary to design self-targeted safety-net programs and targeted subsidies. The primary objective of this study is to investigate the welfare consequences of self-targeted subsidies. In other words, this study tries to find out whether or not transferring one unit of subsidies paid on the subsidized goods mostly used by the rich to the nonsubsidized goods mostly used by the poor improves social welfare. For this purpose, using Atkinson social welfare function, we calculated the change in social welfare caused by self-targeted subsidies. The results show that self-targeted subsidies increase social welfare. The extent of this increase is negatively related to inequality aversion parameter, while positively related to the share of nonsubsidized goods in low income deciles budget.
\end{abstract}

\section{Introduction}

Adoption of a multidimensional method to deprivation applies the challenge of getting insight on the interaction between different dimensions (Atkinson, 1998, 2003). According to Adams (2000), food subsidy programs such as bread are under increasing criticism in most developing countries due to large contributions to government budget deficits (Salevurakis \& Abdel-Haleim, 2008). Many believe food subsidies may influence government's budget and increases poverty (Ali \& Adams, 1996). Alderman and Lindert (1998) reported some evidences from two self-targeting programs, one in South Africa and one in Tunisia on subsidy programs. They explained that although self-targeting could clearly improve the distribution of food subsidies to the poorest members of society, its power to reduce poverty was limited by preference patterns. 


\section{The proposed study}

According to Atkinson $(1998,2003)$, social welfare $(W)$ is defined as follows,

$$
W=\frac{1}{H} \sum_{h=1}^{H}\left(\frac{n_{h}}{1-\varepsilon}\right)\left(\frac{M_{h}}{n_{h}}\right)^{1-\varepsilon} \quad \varepsilon \neq 1
$$

where $M_{h}, n_{h}$ and $H$ represent income, family size, the number of family in population, respectively. In addition, $\varepsilon$ represents the inequality aversion parameter. When $\varepsilon=1$, Eq. (1) becomes as follows,

$W=\frac{1}{H} \sum_{h=1}^{H} n_{h} \operatorname{Ln}\left(\frac{M_{h}}{n_{h}}\right)$.

The utility function of this paper is stated as follows,

$U_{h}=U\left(x_{\vee h}, x_{\ulcorner h}, x_{r h}\right)$,

where $x_{1 h}, x_{2 h}$ and $x_{3 h}$ represent gas, sugar and beans, respectively. The proposed study of this paper uses indirect utility function defined as follows,

$V_{h}=V\left(M_{h}, P\right)$,

where $P$ represent price. Social welfare for each family can be stated as follows,

$\frac{\partial W}{\partial p_{i}}=\sum_{h=1}^{H} \frac{\partial W}{\partial V_{h}} \cdot \frac{\partial V_{h}}{\partial p_{i}} \quad i=1,2,3$

Let $\eta_{h}$ be the marginal social utility of household income of $h$. Therefore, we have

$\frac{\partial W}{\partial p_{i}}=-\sum_{h=1}^{H} \eta_{h} x_{i h} \quad i=1,2,3$

where $I=1,2,3$ represent gas, sugar and beans, respectively. There are two assumptions with our investigations. First, the change on the price of gas and sugar will not change the ratio of $P_{2} / P_{1}$ and the second assumption assumes the total amount welfare is constant, i.e.,

$\frac{d r_{2}}{d r_{1}}=\frac{1-r_{2}}{1-r_{1}}$

where $r_{2}$ and $r_{1}$ represent social welfare paid for sugar and gas, respectively. Generally, the social welfare is paid according to the following relationship,

$r_{i}=\frac{c_{i}-p_{i}}{c_{i}}$

where $c_{i}$ and $p_{i}$ represent the cost of items before and after welfare program, respectively. The welfare of item $i$ for family $h$ is defined as follows,

$w_{i h}=\frac{p_{i} x_{i h}}{M_{h}}$.

In addition, the portion of each family from social welfare is characterized as follows, 
$w_{i}^{\varepsilon}=\frac{\sum_{h=1}^{H} \eta_{h} \cdot w_{i h} \cdot M_{h}}{\sum_{h=1}^{H} M_{h}}$.

Therefore, we have,

$$
w_{i}^{\varepsilon}=\sum_{h=1}^{H}\left(\frac{M_{h}}{n_{h}}\right)^{-\varepsilon} \cdot w_{i h} \cdot \frac{M_{h}}{\sum_{h=1}^{H} M_{h}}
$$

and

$\Delta W=-\left(\frac{d p_{1}}{d r_{1}}\right) \sum_{h=1}^{H} \eta_{h} x_{1 h}-\left(\frac{d p_{2}}{d r_{2}} \cdot \frac{d r_{2}}{d r_{1}}\right) \sum_{h=1}^{H} \eta_{h} x_{2 h}-\left(\frac{d p_{3}}{d r_{3}}\right)\left(\frac{d r_{3}}{d r_{1}}\right) \sum_{h=1}^{H} \eta_{h} x_{3 h}$.

Using the relationships stated previously we have

$\Delta W=H \bar{M}\left[\frac{w_{1}^{\varepsilon}}{1-r_{1}}+\frac{w_{2}^{\varepsilon}}{1-r_{1}}+\left(\frac{d r_{3}}{d r_{2}}\right) \frac{w_{3}^{\varepsilon}}{1-r_{3}}\right]$.

where $\bar{M}=\frac{\sum_{h=1}^{H} M_{h}}{H}$. A standard model for estimating demand is as follows,

$w_{i}=\beta_{i} \bar{M}+\left(\theta_{i 1}+\theta_{i 2}\right) P_{i}+\left(\theta_{j 1}+\theta_{j 2}\right) P_{j}+u_{i}$.

For each family, we may write the equation as follows,

$w_{i h}=\beta_{i} M_{h}+\left(\theta_{i \backslash}+\theta_{i\ulcorner}\right) P_{i}+\left(\theta_{j \backslash}+\theta_{j \curlyvee}\right) P_{j}+u_{i}$.

with

$$
\frac{\partial w_{i h}}{\partial p_{j}}=\frac{\theta_{j 1}+\theta_{j 2}}{1-r_{j}} \quad i \neq j
$$

Total amount of welfare paid for commodity $i$ is calculated as follows,

$$
S_{i}=\sum_{h=1}^{H}\left(c_{i}-p_{i}\right) x_{i h},
$$

and

$$
S_{i}=\sum_{h=1}^{H}\left(\frac{r_{i}}{1-r_{i}}\right) p_{i} x_{i h}=\sum_{h=1}^{H}\left(\frac{r_{i}}{1-r_{i}}\right) w_{i h} M_{h} .
$$

Therefore, total amount of welfare paid to all three commodities are calculated as follows, 
$S=S_{1}+S_{r}+S_{r}=\sum_{i=1}^{r} S_{i}=\sum_{i=1}^{r} \sum_{h=1}^{H}\left(\frac{r_{i}}{1-r_{i}}\right) w_{i h} M_{h}$.

Besides, the changes of welfare paid is calculated as follows,

$\Delta S=\sum_{i=1}^{3} \frac{\partial s_{i}}{\partial r_{1}}+\sum_{j=2}^{3} \sum_{i=1}^{3} \frac{\partial S_{i}}{\partial r_{j}} \frac{d r_{j}}{d r_{1}}$

Since $\Delta S=0$ therefore we have,

$\frac{d r_{r}}{d r_{\uparrow}}=-\frac{\sum_{i=1}^{r}\left[\frac{\partial S_{i}}{\partial r_{\uparrow}}+\frac{\partial S_{i}}{\partial r_{r}} \cdot \frac{d r_{r}}{d r_{\uparrow}}\right]}{\sum_{i=1}^{r} \frac{\partial S_{i}}{\partial r_{r}}}$

and since government does not pay subsidy for beans, i.e. $r_{3}=0$, we have

$$
\Delta S_{1}=\frac{1}{\left(1-r_{1}\right)^{2}} \sum_{h=1}^{H} w_{1 h} M_{h}+\frac{r_{1}}{1-r_{1}} \sum_{h=1}^{H} M_{h}\left(\frac{\partial w_{1 h}}{\partial r_{1}}\right)+\frac{r_{1}}{1-r_{1}} \sum_{h=1}^{H} M_{h}\left(\frac{\partial w_{1 h}}{\partial r_{2}}\right)\left(\frac{d r_{2}}{d r_{1}}\right) \text {. }
$$

Using

$\bar{M}=\frac{\sum_{h=1}^{H} M_{h}}{H}, \quad w_{i}=\frac{\sum_{h=1}^{H} w_{1 h} M_{h}}{\sum_{h=1}^{H} M_{h}}$

or

$\Delta S_{1}=\frac{H w_{1} \bar{M}}{\left(1-r_{1}\right)^{2}}\left[1+\frac{r_{1}}{w_{1}}\left(\theta_{11}+\theta_{12}\right)\right]$

and

$\Delta S_{2}=\frac{H w_{2} \bar{M}}{\left(1-r_{1}\right)\left(1-r_{2}\right)}\left[1+\frac{r_{2}}{w_{2}}\left[\theta_{21}+\theta_{22}\right]\right]$

Substituting $r_{3}=0$ yields

$D=H w_{3} \bar{M}\left\{1-\left[\left(\frac{r_{1}}{1-r_{1}}\right)\left(\frac{\theta_{13}+\theta_{23}}{w_{3}}\right)+\left(\frac{r_{2}}{1-r_{2}}\right)\left(\frac{\theta_{13}+\theta_{23}}{w_{3}}\right)\right]\right\}$

The rate of changes of beans respect to sugar is calculated as follows,

$$
\frac{d r_{3}}{d r_{1}}=\frac{\left[\frac{w_{1}}{\left(1-r_{1}\right)^{2}}\right]\left[1+\frac{r_{1}}{w_{1}}\left(\theta_{11}+\theta_{12}\right)\right]+\left[\frac{w_{2}}{\left(1-r_{1}\left(1-r_{2}\right)\right.}\right]\left[1+\frac{r_{2}}{w_{2}}\left(\theta_{21}+\theta_{22}\right)\right]}{w_{3}\left\{1-\left[\left(\frac{r_{1}}{1-r_{1}}\right)\left(\frac{\theta_{13}+\theta_{23}}{w_{3}}\right)+\left(\frac{r_{2}}{1-r_{2}}\right)\left(\frac{\theta_{13}+\theta_{23}}{w_{3}}\right)\right]\right\}}
$$




\section{The results}

In this section, we present details of our findings on testing the historical data. Table 1 shows details of some basic statistics on shares of three basic foods, i.e. gas, sugar and beans.

\section{Table 1}

The summary of some basic statistics

\begin{tabular}{lccc}
\hline Year & Shares of family income on Gas & Shares of family income on Sugar & Shares of family income on Beans \\
\hline 1988 & 0.05 & 0.007 & 0.006 \\
1989 & 0.04 & 0.008 & 0.010 \\
1990 & 0.06 & 0.007 & 0.013 \\
1991 & 0.06 & 0.010 & 0.011 \\
1992 & 0.010 & 0.016 & 0.011 \\
1993 & 0.166 & 0.039 & 0.009 \\
1994 & 0.237 & 0.011 & 0.019 \\
1995 & 0.109 & 0.014 & 0.013 \\
1996 & 0.143 & 0.006 & 0.009 \\
1997 & 0.070 & 0.007 & 0.003 \\
1998 & 0.083 & 0.007 & 0.005 \\
1999 & 0.077 & 0.006 & 0.006 \\
2000 & 0.090 & 0.006 & 0.006 \\
2001 & 0.118 & 0.022 & 0.006 \\
2002 & 0.0124 & 0.009 & 0.006 \\
2003 & 0.177 & 0.006 & 0.007 \\
2004 & 0.158 & 0.006 & 0.005 \\
2005 & 0.199 & 0.006 & 0.006 \\
2006 & 0.202 & 0.019 & 0.007 \\
2007 & 0.212 & & 0.009 \\
\hline
\end{tabular}

The proposed study of this paper gathers the same information over the same period mentioned in Table 1 and the following regression analysis is performed.

$$
w_{i}=a_{i 1}+a_{i 2} m+a_{i 3} p_{1 r}+a_{i 4} p_{2 r}+a_{i 5} p_{3 r}+u_{i} \quad i=1,2,3
$$

The first step to perform the regression statistics is to make sure that the data are stationary and this is confirmed through Augmented Dickey-Fuller (ADF) test. Table 3 shows details of ADF test.

\section{Table 3}

The summary of ADF test

\begin{tabular}{lccccccc}
\hline Variable & $w_{1}$ & $w_{2}$ & $w_{3}$ & $p_{1 r}$ & $P_{2 r}$ & $P_{3 r}$ & $m$ \\
\hline Statistics & -5.25 & -5.96 & -4.97 & -3.54 & -3.41 & -2.93 & -6.07 \\
Critical value & -1.96 & -1.96 & -1.96 & -1.96 & -1.96 & -1.96 & -1.96 \\
\hline
\end{tabular}

The results of Table 3 clearly show that all variables become stationary after taking one difference between variables. In addition, Engle-Granger cointegration test has been applied on residuals and Table 4 shows the results of our survey.

\section{Table 4}

The summary of Engle-Granger cointegration test

\begin{tabular}{lccc}
\hline Statistics & $\mathrm{e}_{1}$ & $\mathrm{e}_{2}$ & $\mathrm{e}_{3}$ \\
\hline Value & -5.6 & -4.71 & -4.51 \\
Critical value & -4.32 & -4.32 & -4.32 \\
\hline
\end{tabular}

Eq. (29) to Eq. (31) demonstrate the results of regression estimation.

$$
\begin{aligned}
& \hat{w}_{1}=0.03-0.009 m-0.01 p_{1 r}-0.002 p_{2 r}+0.01 p_{3 r} \\
& \hat{w}_{2}=0.005-0.007 m-0.008 p_{1 r}+0.0005 p_{2 r}+0.001 p_{3 r} \\
& \hat{w}_{3}=0.014-0.005 m-0.003 p_{1 r}+0.0005 p_{2 r}+0.0003 p_{3 r}
\end{aligned}
$$


In our study, we considered year 2007 prices for gas and sugar as a basis for estimation and Table 5 shows details of the prices.

\section{Table 5}

The summary of prices of gas and sugar

\begin{tabular}{lccc}
\hline Commodity & Subsidized price & Non-subsidized price & Social welfare rate \\
\hline Gas & 1000 & 4545 & 0.78 \\
Sugar & 2000 & 5670 & 0.65 \\
\hline
\end{tabular}

Using Eq. (27), the changes of beans respect to sugar is $\frac{d r_{3}}{d r_{2}}=379.64$. Table 6 demonstrates the change on social welfare based on various values of $\varepsilon$.

\section{Table 6}

The summary of change on social welfare

\begin{tabular}{lcccc}
\hline$\varepsilon$ & $\varepsilon=0$ & $\varepsilon=1$ & $\varepsilon=1.5$ & $\varepsilon=2$ \\
\hline$\left(\frac{\Delta W}{H \bar{M}}\right)$ & 4.463 & 0.453 & 0.254 & 0.124 \\
\hline
\end{tabular}

The results of Table 6 show that social welfare for the first four groups of people is increased while the social welfare for the rest of groups is reduced. In other words, the results indicate that poor people may benefit from the changes of the prices.

\section{Conclusion}

During the past few years, there have been different discussions in Iranian society on eliminating any subsidy programs especially on energy and some basic foods such as sugar and beans. This study has examined the effect of change on prices of gas and sugar on social welfare. The results of our survey have indicated that the program could reduce the gap between rich and poor people. In other words, social welfare for the first four groups of people has been increased while the social welfare for the rest of groups was reduced. In other words, the results indicate that poor people may benefit from the changes of the prices. The results show that self-targeted subsidies increase social welfare. The extent of this increase is negatively related to inequality aversion parameter, while positively related to the share of nonsubsidized goods in low income deciles budget.

\section{References}

Adams, R. H. (2000). Self-targeted subsidies: the distributional impact of the Egyptian food subsidy system (Vol. 2322). World Bank Publications.

Alderman, H., \& Lindert, K. (1998). The potential and limitations of self-targeted food subsidies. The World Bank Research Observer, 13(2), 213-229.

Ali, S. M., \& Adams Jr, R. H. (1996). The Egyptian food subsidy system: Operation and effects on income distribution. World Development, 24(11), 1777-1791.

Atkinson, A. B. (1998). Social exclusion, poverty and unemployment. Exclusion, Employment and Opportunity, 4.

Atkinson, A. B. (2003). Multidimensional deprivation: contrasting social welfare and counting approaches. The Journal of Economic Inequality, 1(1), 51-65.

Salevurakis, J. W., \& Abdel-Haleim, S. M. (2008). Bread subsidies in Egypt: Choosing social stability or fiscal responsibility. Review of Radical Political Economics, 40(1), 35-49. 